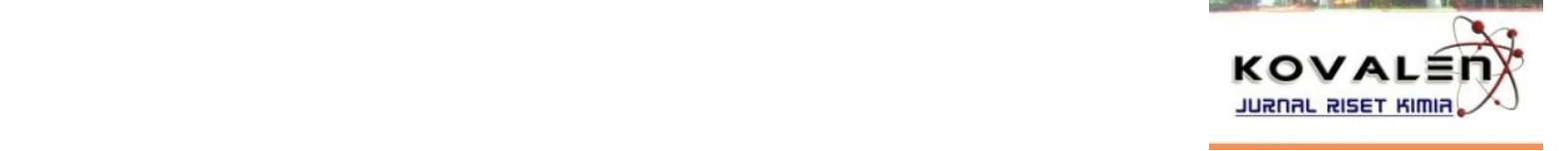

\title{
STUDI REAKSI SENYAWA SITRONELAL DENGAN L-TIROSINA DAN UJI AKTIVITAS ANTIBAKTERI TERHADAP Staphylococcus aureus
}

\section{[Study of Citronellal With L-Tyrosin Reaction and Antibacterial Activity Test to The Staphylococcus aureus]}

\author{
Famri Rusdin $^{1^{\star}}$, Hardi Ys ${ }^{1}$, Syamsuddin ${ }^{1}$ \\ 1) Jurusan Kimia Fakultas MIPA, Universitas Tadulako \\ Jl. Soekarno Hatta Km.9, Kampus Bumi Tadulako Tondo Palu, Telp. 0451- 422611 \\ *)Coresponding author: fam.rusdin@gmail.com (hp. +6285342814473)
}

Diterima 27 Desember 2017, Disetujui 10 April 2018

\begin{abstract}
Modification and synthesis of chemical compounds research for antibacterial purposes still continue to develop, among them is the study of the relationship between the structure of compounds with antibacterial activity. This study conducted a reaction of two compounds, citronellal and L-tyrosine which closely related to the relationship between structure of compounds and antibacterial activity against Staphylococcus aureus. The reaction used the schiff base method by refluxing the mixture with $\mathrm{KOH}$ catalyst at $60^{\circ} \mathrm{C}$ for 8 hours. The reaction product was characterized by TLC and IR spectrophotometry. The synthesized result produces yellow solid amorphous compound of 0.061 gram with the melting point of $265-269^{\circ} \mathrm{C}$. Antibacterial testing of Staphylococcus aureus which used dilution method showed a weak inhibition at a concentration of $1200 \mu \mathrm{g} / \mathrm{mL}$. However, this antibacterial properties indicate that the product has relationship to structure compound.
\end{abstract}

Keywords: Citronellal, L-tyrosin, antibacterial activity, Staphylococcus aureus.

\begin{abstract}
ABSTRAK
Penelitian modifikasi dan sintesis senyawa kimia untuk tujuan antibakteri terus berkembang, diantaranya adalah kajian hubungan antara struktur senyawa dengan aktivitas antibakteri. Penelitian ini dilakukan melalui kajian reaksi dua senyawa yaitu sitronelal dan L-tirosinaa yang ada hubungannya antara struktur senyawa dan aktivitas antibakteri terhadap Staphylococcus aureus. Reaksi tersebut menggunakan metode schiff base dengan cara merefluks campuran dengan katalis $\mathrm{KOH}$ pada suhu $60^{\circ} \mathrm{C}$ selama 8 jam. Hasil reaksi dikarakterisasi dengan KLT dan Spekrofotometri IR. Senyawa hasil sintesis berbentuk padatan amorf berwarna kuning dengan berat 0,061 gram beserta titik leleh $265-269^{\circ} \mathrm{C}$. Hasil pengujian antibakteri terhadap Staphylococcus aureus menggunakan metode dilusi pada konsentrasi $1200 \mu \mathrm{g} / \mathrm{mL}$. Sifat antibakteri hasil reaksi mengindikasikan masih adanya hubungan struktur senyawa dengan aktivitas yang lemah.
\end{abstract}

Kata kunci : Sitronelal, L-tirosina, Aktivitas antibakteri, Staphylococcus aureus. 


\section{LATAR BELAKANG}

Penyakit infeksi oleh bakteri dan fungi merupakan jenis penyakit yang paling banyak diderita oleh penduduk, terutama di negara berkembang, seperti Indonesia. Staphylococcus aureus merupakan salah satu bakteri patogen yang sering menyebabkan penyakit infeksi, nekrosis dan pembentukan asbes (Warsa, 1993).

Sehingga peningkatan produksi terhadap produk antibakteri dari tahun ke tahun meningkat. Antibakteri merupakan senyawa kimia yang digunakan untuk mematikan bakteri-bakteri patogen (Agustrina, 2011).

Senyawa maupun produk anti bakteri bersumber dari produk alami dan buatan. Senyawa antibakteri umumnya berasal dari hasil isolasi sumber daya alam hayati khususnya tumbuh-tumbuhan baik daun, batang dan akar. Senyawa (selanjutnya disebut senyawa alami) ini terbukti selain bersifat anti bakteri juga ramah terhadap sel mamalia termasuk manusia.

Senyawa hasil sintesis, tidak seperti halnya senyawa alami, sebagian besar terkendala pada efek yang kurang baik terhadap sel mamalia, sebagaimana diketahui bahwa manusia tergolong mamalia. Meskipun demikian, aspek waktu, ekonomi, efisiensi dan produktivitas senyawa buatan jauh lebih baik dan terukur. Oleh karenanya penelitian sintesis senyawa tetap berlangsung dan berkembang dengan mempertimbangkan kaidah sesuai peruntukannya.
Keunggulan dalam produksi senyawa buatan disertai kajian detail tentang fungsi dan dampaknya menjadikan senyawa buatan pilihan yang menjanjikan baik efisensi dan efektifitas penggunaannya. Uraian di atas menginspirasi dilakukannya kajian mendasar tentang keilmuan dan kemungkinan aplikasinya, dalam hal ini memahami fenomena struktur molekul senyawa kimia terkait aktivitasnya sebagai antibakteri dan memiliki kompatibilitas terhadap sel mamalia. Kajian tersebut terkait dengan struktur senyawa yang memiliki dua rangkaian gugus alifatik asimetrik (prenil) dan gugus aromatik-hidroksil. Kajian ini diuraikan secara detil pada bab tinjauan kepustakaan.

Dipahami secara umum bahwa struktur senyawa kimia berkaitan dengan sifat dan fungsinya. Beberapa penelitian (Rukayadi and Hwang, 2006; Steffensky et al., 1998; Johnston et al., 1987; Lewis dan Klibanov, 2005) menunjukan adanya kesamaan struktur kimia yang memiliki aktivitas sebagai antibakteri. Senyawa kimia tersebut adalah novobiocin, serrulatane, dan xanthorhizol.

Berbagai penelitian yang telah dilakukan, maka peneliti ingin mereaksikan suatu senyawa yang berpotensi sebagai antibakteri, di mana bahan yang digunakan adalah sitronelal dan asam amino tirosin. Sitronelal (3,7dimetil-6-oktenal) mempunyai gugus aldehida ikatan rangkap dan rantai karbon (Agustin et al., 2007), serta asam amino 
tirosin mempunyai gugus aromatikhidroksil.

\section{METODE PENELITIAN}

\section{Bahan dan Peralatan}

Bahan yang digunakan adalah sitronellal, L-tirosin, metanol, $\mathrm{KOH}$, dietil eter, etanol 96\%, bakteri Staphylococcus aureus, akuades, $\mathrm{NaCl}$ fisiologis, Dimetil sulfoksida (DMSO), Brain Heart Infusion Broth (BHIB) dan Nutrien Agar (NA).

Alat-alat yang digunakan meliputi alat-alat gelas yang biasa digunakan dalam penelitian kimia organik. Alat pendukung seperti seperangkat alat refluks, spektronik 20, Spektrofotomter IR, inkubator, vorteks, bunsen, autoklaf, neraca analitik, pipet ependrof, laminar air flow.

\section{Prosedur Penelitian}

\section{Sintesis senyawa (Al-Garawi et al, 2012)}

Sebanyak 0,18 gram sitronelal $(1,2$ $\mathrm{mmol}$ ) dalam $10 \mathrm{~mL}$ metanol direaksikan dengan 0,18 gram asam amino L-tirosina (1 mmol) dalam $15 \mathrm{~mL}$ metanol, lalu ditambahkan 0,056 gram $\mathrm{KOH}$. Campuran direfluks pada suhu $60^{\circ} \mathrm{C}$ selama 8 jam. Selanjutnya hasil reaksi dipekatkan dan dicuci dengan etanol. Kemudian dicuci kembali dengan dietil eter dan diuapkan pada suhu ruang. Dianalisis dengan spektrofotometer IR

Uji Aktivitas Antibakteri (Deby et al., 2012).

Metode dilusi cair dilakukan dengan menyiapkan beberapa botol kaca yang sudah steril, larutan uji dan bakteri uji sebagai kontrol negatif. Selanjutnya tiaptiap botol kaca diisi dengan $0,5 \mathrm{~mL}$ medium BHIB. Selanjutnya ditambahkan 0,5 mL larutan uji pada botol kaca pertama dan di vortex. Dari tabung pertama diambil $0,5 \mathrm{~mL}$ dipindahkan kedalam tabung kedua dan seterusnya sampai konsentrasi $75 \%$. Lalu diambil 0,5 $\mathrm{mL}$ larutan pada botol terakhir dan dibuang, sehingga masing-masing tabung berisi $0,5 \mathrm{~mL}$. Kemudian masing-masing botol $0,1 \mathrm{~mL}$ suspensi bakteri dan $0,4 \mathrm{~mL}$ $\mathrm{BHIB}$ dengan volume masing-masing botol kaca $1 \mathrm{~mL}$ dan di vortex. Selanjutnya diinkubasi pada suhu $37^{\circ} \mathrm{C}$ selama 24 jam. Selanjutnya Masingmasing tabung diencerkan dalam $10 \mathrm{~mL}$ akuades steril dan diukur absorbansinya pada $\lambda 625 \mathrm{~nm}$.

\section{HASIL DAN PEMBAHASAN}

\section{Senyawa Hasil Sintesis}

Reaksi yang dilakukan antara sitronelal dan L-tirosina yakni reaksi schiff base dengan menggunakan katalis $\mathrm{KOH}$, dimana campuran direfluks selama 8 jam pada suhu $60^{\circ} \mathrm{C}$. Menurut Riswiyanto (2009) reaksi adisi nukleofilik amina primer terhadap aldehida atau keton akan menghasilkan senyawa imina, $\mathrm{R}_{2} \mathrm{C}=\mathrm{NR}$. Selain itu, kemungkinan senyawa lain yang terbentuk adalah terjadinya adisi nukleofilik pada struktur benzen, dimana gugus karbonil pada sitronelal terkonjugasi pada pengarah orto benzen.

Berat yang diperoleh 0,061 gram serta bentuk fisik berupa padatan amorf 
berwarna kuning beraroma wangi dan kurang tajam dibanding sitronelal. Hasil penentuan titik leleh senyawa produk, diperoleh titik leleh $265-269^{\circ} \mathrm{C}$. Penentuan titik leleh juga dilakukan pada senyawa sitronelal dan L-tirosina dengan hasil masing-masing $208^{\circ} \mathrm{C}$ dan $323^{\circ} \mathrm{C}$. Namun, jika dilihat dari struktur L-tirosina dan dibandingkan dengan prediksi struktur produk, maka seharusnya senyawa produk akan memiliki titik leleh yang lebih tinggi dari titik leleh L-tirosina. Hal ini memberikan kemungkinan terbentuknya senyawa baru yang bukan merupakan senyawa target.

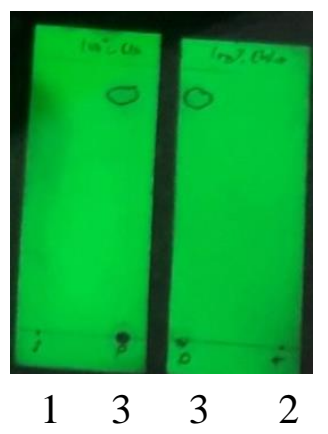

Keterangan:

1. Sitronellal

2. Tirosin

3. Produk
Gambar 1 Hasil KLT senyawa sintesis

Hasil KLT menunjukkan noda tunggal tidak berekor pada hasil reaksi dengan Rf sebesar 0,85, namun sitronelal (1) dan L-tirosin (2) tidak ada noda yang terbentuk. Hal ini disebabkan kepolaran produk dan kedua senyawa berbeda.

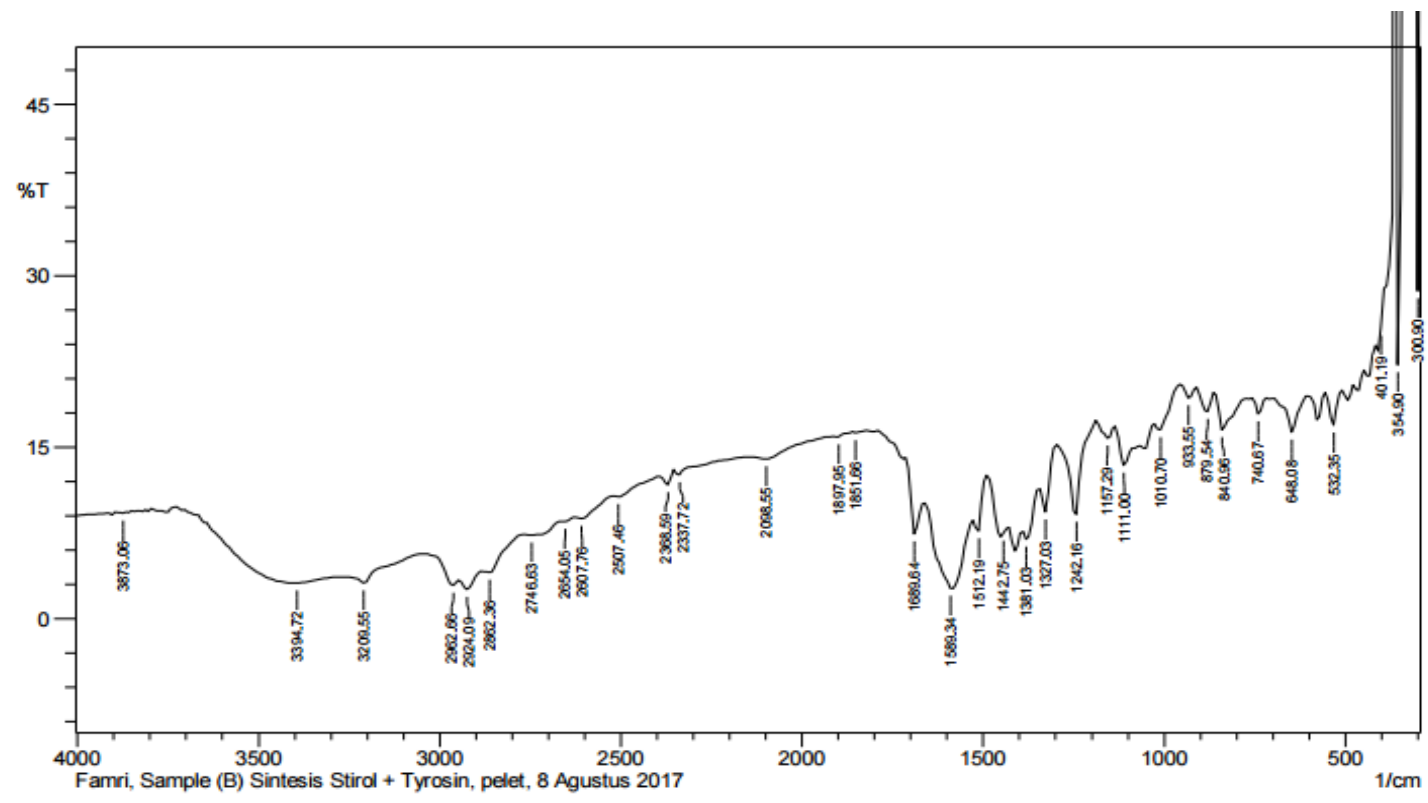

Gambar 2 Spektrum IR senyawa hasil sintesis

Gambar 2 menunjukkan adanya perbedaan dari dua spektrum di atas, di mana adanya serapan $\mathrm{C}=\mathrm{O}$ terkonjugasi pada bilangan gelombang $1689 \mathrm{~cm}^{-1}$ dengan intensitas medium. Pula terdapat serapan kuat $\mathrm{OH}$ pada bilangan gelombang $3016 \mathrm{~cm}^{-1}$ serta munculnya peak pada bilangan gelombang $3209 \mathrm{~cm}^{-1}$ merupakan ikatan $\mathrm{N}-\mathrm{H}$ dengan intensitas lemah. Hal ini menujukkan senyawa yang diperoleh masih terdapat senyawa awal

\section{Aktivitas Antibakteri}

Aktivitas antibakteri ditinjau melalui tingkat kekeruhan medium. Hubungan antara konsentrasi terhadap nilai 
absorbansi senyawa berbanding lurus (Gambar 3). Artinya, makin tinggi konsentrasi yang digunakan akan menyebabkan penurunan nilai absorbansi. Hal ini dikarenakan oleh tingkat kekeruhan yang semakin rendah. Kekeruhan ini menujukkan adanya aktivitas bakteri.

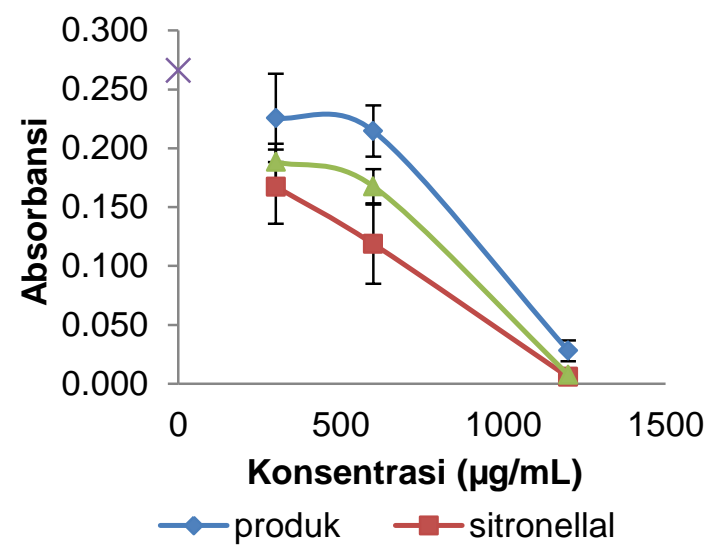

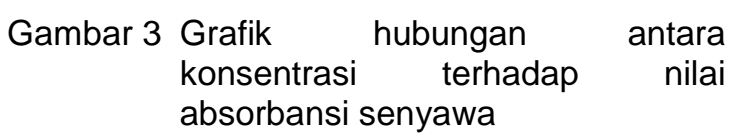

Pada kontrol medium diperoleh absorbansi 0,000 yang berarti tidak adanya pertumbuhan bakteri, sedangkan pada kontrol negatif absorbansi yang diperoleh sebesar 0,292 menunjukkan pertumbuhan bakteri yang banyak. Senyawa hasil reaksi menunjukkan absorbansi yang lebih tinggi dibandingkan sitronelal dan L-tirosina. Hal ini menunjukkan senyawa tersebut kurang reaktif menghambat sel bakteri.

\section{KESIMPULAN}

Berdasarkan hasil penelitian, dapat disimpulkan bahwa diasumsikan terjadi reaksi antara sitronelal dan L-tirosina serta terbentuknya senyawa baru dengan berat 0,061 gram serta sifat fisik berbentuk padatan amorf berwarna kuning yang memiliki titik leleh $265-269^{\circ} \mathrm{C}$, serta senyawa hasil reaksi memiliki aktivitas antibakteri yang lemah.

\section{DAFTAR PUSTAKA}

Agustin, E., Sulaswatty, A., Tasrif, Laksmon, J.A., Adilina, B. (2007). Pemisahan sitronellal dari minyak wangi sereh wangi menggunakan unit fraksionasi skala bench. Jurnal Teknologi Industri Pertanian, 17(2): 49-53.

Agustrina, G. (2011). Potensi propolis lebah madu Apis melifera sebagai bahan antibakteri. Skripsi. Bogor: Departemen Biokimia, Fakultas Matematika dan IImu Pengetahuan Alam Institut Pertanian Bogor.

Al-Garawi, Z. S., Tomi, I. H., Al-Daraji, A. $H$. (2012). Synthesis and characterization of new amino acid schiff bases and studies their effects on the activity of ACP, PAP and NPA enzymes (In vitro). E-journal of Chemistry, 9(2): 962-969.

Deby, A., Mpila, L., Fatmawati, Weny, I., Wiyono. (2012). Uji aktivitas antibakteri ekstrak etanol daun mayana (Coleus atropurpureus benth) terhadap Staphylococcus aureus, Eschericia coli dan Pseudomonas aeruginosa secara in vitro.

Lewis, A., Klibanov, A. (2005). Surprising nature: Rational design of sterilesurface materials. Trends in Biotechnology, 23(7): 343-348.

Riswiyanto. (2009). Kimia organik edisi kedua. Jakarta: Erlangga.

Rukayadi, Y., Hwang, J. (2006). Effect of coating the wells of a polystyrene microtiter plate with xhantorrizhol on the biofilm formation of Streptococcus mutans. Journal of Basic Microbiology, 46(5): 410-415. 
Steffensky, M., Li, S., Vogler, B., Heide, L. (1998). Novobiocin biosynthesis in Streptomyces spheroides: Identification of a dimethylallyl diphosphate: 4hydroxyphenylpyruvate dimethylallyl transferase. FEMS Microbiology Letters, 161(1): 69-74.

Warsa, U. C. (1993). Buku ajar Mikrobiologi Kedokteran: Kokus positif gram. Jakarta: Binarupa Aksara. 